\title{
BMJ Open Experiences of pregnant mothers using a social media based antenatal support service during the COVID-19 lockdown in the UK: findings from a user survey
}

\author{
John Chatwin (D , ${ }^{1}$ Danielle Butler, ${ }^{1}$ Jude Jones, ${ }^{1}$ Laura James, ${ }^{1}$ Lesley Choucri, ${ }^{1}$ \\ Rose McCarthy ${ }^{2}$
}

To cite: Chatwin J, Butler D, Jones $\mathrm{J}$, et al. Experiences of pregnant mothers using a social media based antenatal support service during the COVID-19 lockdown in the UK: findings from a user survey. BMJ Open 2021;11:e040649. doi:10.1136/ bmjopen-2020-040649

- Prepublication history for this paper is available online. To view these files, please visit the journal online (http://dx.doi org/10.1136/bmjopen-2020040649).

Received 19 May 2020 Revised 14 October 2020 Accepted 05 November 2020

Check for updates

(C) Author(s) (or their employer(s)) 2021. Re-use permitted under CC BY-NC. No commercial re-use. See rights and permissions. Published by BMJ.

${ }^{1}$ School of Nursing, Midwifery, Social Work and Social Science, University of Salford School of Nursing Midwifery and Social Work, Manchester, UK

${ }^{2}$ Health Education England, Manchester, UK

Correspondence to

Dr John Chatwin;

john.chatwin@nhs.net

\section{ABSTRACT}

Objectives The COVID-19 pandemic has seen

unprecedented restrictions on face-to-face healthcare encounters. This has led to an increase in the use of online healthcare resources by service users. Pregnant women have always been a group particularly motivated to seek out information online. The objective of this study was to explore the experiences of mothers who were using an existing National Health Service social media based antenatal support service during the early stages of the UK COVID-19 lockdown.

Design A short online survey with four closed questions (scale response) and one open-ended free-text question was given to pregnant women who were using the online service 3 weeks after the start of the UK lockdown. Descriptive statistics are used to present the closed question data. Thematic analysis was applied to the freetext responses.

Results 320 women were sent the survey. 156 completed it (49\% response rate). Participants provided information relating to frequency of use, information access, relative level of antenatal care and ease of contact. 105 (66\%) participants completed the open-ended free-text question. Key themes to emerge related to: (1) information provision and verification; (2) managing and reducing feelings of isolation; (3) service specific issues, including crisis adaptations; and (4) impact on routine care.

Conclusions The study suggests that that pregnant mothers found a social media based approach well positioned to provide antenatal care and support during the COVID-19 pandemic.

\section{BACKGROUND}

The COVID-19 pandemic has seen unprecedented restrictions on face-to-face healthcare encounters throughout the world. One effect of this has been an exponential increase in the use of online healthcare resources by people seeking non-urgent healthcare advice and support. ${ }^{12}$ Well before COVID-19, widespread internet availability had fundamentally changed the way many people accessed health information and engaged with health providers. ${ }^{3}$ While it is widely acknowledged
Strengths and limitations of this study

- This survey-based study explored the experiences of pregnant women accessing an online maternity support service during the COVID-19 pandemic.

- Approximately half of the women using the service responded to the survey.

- The design of the survey may have introduced a positive bias towards the service, and detailed demographic information was not collected.

- Only women who were already using the service at the time of COVID-19 were sampled, which could have influenced their attitude towards social media based support and the issues they chose to report.

- The moderate response rate and lack of sociodemographic data on respondents may limit the generalisability of the study.

that much healthcare-related information available on the internet is of dubious provenance and can be difficult for people to verify, ${ }^{4}$ there has always been a drive by qualified healthcare professionals and their organisations to counter this by providing professionally sanctioned healthcare support and information of all kinds online. ${ }^{5}$

Pregnant women have always been particularly motivated to seek out information online, ${ }^{67}$ and the popularity of social media based interventions as a source of information and support for this group has been growing for a number of years. In addition to being able to access significantly more maternity-related information through the internet, many pregnant women also now become members of online communities ${ }^{8}$ where they can meet other mothers, share experiences, offer each other social and emotional support and ask and answer questions. ${ }^{9}$ Social media use by women of childbearing age in the UK is extremely high, with $93 \%$ of $16-24$ year olds, $88 \%$ of 24-34year 
olds and $85 \%$ of $35-44$ year olds now classing themselves as active users. ${ }^{10}$ Groups specifically aimed at pregnant women have similarly become much more common over the past decade ${ }^{9}$ and added to these are a multitude of privately hosted groups on general social media platforms such as Facebook or Twitter.

In this article, we present an analysis of feedback collected from a survey of pregnant mothers who were using a midwife-moderated social media based support service during the early stages of UK lockdown during the COVID-19 outbreak. The service, called Facemums (see Acknowledgements) is an online initiative that is currently being piloted in maternity units in 12 National Health Service (NHS) Trusts in England. It offers pregnant women the opportunity to join private maternity-related online discussion groups, hosted on the Facebook social media platform. Importantly, groups are private, and invitation is via NHS maternity services referral only. Individual groups have a maximum of 20 pregnant mothers and are moderated by two qualified midwives. These midwives, called Facewives, work together to verify information shared among their group, answer specific queries, signpost to other relevant services and sources, and offer evidence-based maternityrelated advice. Participating NHS maternity units may have several groups running simultaneously. Two senior midwives and a project manager based at the University of Salford oversee the organisation and running of the service and provide training and mentorship the midwife moderators.

A parallel aim of the initiative is to help pregnant mothers develop their own 'virtual' communities of care $^{11}$ where they can support each other and share their personal experiences and information. An important role of the moderators is therefore to closely monitor these ongoing interactions (ie, messages posted by mothers on their group). Then, if necessary, they may step in to offer confirmation, clarify misunderstandings or correct any inaccurate and misleading information that may be shared. Moderators check their group at least once a day in order to do this. A detailed outline of the service model and preliminary evaluation findings are presented elsewhere. ${ }^{11} 12$ Any pregnant mothers attending a maternity unit at a participating Trust who are greater than 15 weeks' gestation are eligible to join Facemums. All mothers who were part of an active group at the time of the current study were eligible to complete the survey.

\section{OBJECTIVE}

The objective of the study was to explore the experiences of mothers who were using the Facemums service during the early stages of the initial COVID-19 UK lockdown. We also sought to examine those features of the service that were reported by mothers to be most useful as the crisis progressed.

\section{METHODS}

\section{Facemums evaluation}

This was a standalone survey study conducted as part of an ongoing mixed-methods evaluation of the Facemums service. The wider evaluation includes regular mixed methods surveys to gather qualitative and experiential information, along with a validated measure (the Quality of Prenatal Care Questionnaire). These are posted online at 10-week interval. Content, thematic and narrative analysis of interactions taking place between participants on their groups is also being undertaken, along with the sociolinguistic analysis of selected online activity.

\section{Survey design and content}

The COVID-19 focused survey discussed here was developed by the two senior midwives managing the service with input from the wider research team. It consisted of four short statements that participants were asked to rate using a 5-point Likert scale ranging from 'strongly agree' to 'strongly disagree'. The survey also included a final open question that required a free-text response.

\section{Survey process}

All pregnant mothers who were members of a Facemums group at a participating NHS maternity unit were eligible to take part in the study and were sent a link to the electronic survey by one of the senior midwives. The senior midwives were also responsible for the survey design. There was input from the wider Facemums advisory group and Patient and Public Involvement representatives, but due to time constraints, this was limited. The survey was built using the Jisc online survey tool $^{13}$ and hosted on a secure server at the University of Salford. The maternity units involved in the study were based at: Royal Bolton Hospital, Ingleside Birth and Community Centre (Bolton NHS Foundation Trust), Warwick Hospital and Bluebell Birth Centre (South Warwickshire NHS Foundation Trust), Liverpool women's NHS Foundation Trust, Stepping Hill Hospital (Stockport), Leeds General Infirmary and St James's University Hospital (Leeds).

The survey was electronic (ie, completed online) and launched on 16 April 2020, approximately 3 weeks into the first full UK lockdown. It remained open for a relatively short period ( 1 week) to enable analysis to be undertaken at speed and for it to remain relevant to the current context. Significantly, the majority of respondents who took part sent their replies within 24 hours of receiving the survey. As a precondition of joining a Facemums group, participants had already consented to receiving regular evaluation surveys, so consent to participate in this survey was assumed if it was completed and submitted.

\section{Changes to maternity services due to COVID-19}

The response to COVID-19 from individual Trusts and maternity units differed. However, in general, there were widespread reductions in face-to-face appointments and home visits. Maternity units operated a significantly reduced service and provided phone or online support 
where possible. Birth partners were not allowed to be present until the onset of labour, and mothers had to attend for scans alone.

At a practical level, the Facemums groups that were already active during lockdown continued to operate in much the same way. However, a number of adaptations were made as the situation developed. These included allowing extra non-clinical maternity staff at participating units to join groups and act as support for the midwife moderators. Moderators were also encouraged to start dedicated threads solely for COVID-19 related concerns.

\section{Analysis}

Descriptive statistics were used to provide a summary of the key findings from the closed questions. Responses to the free-text question were analysed thematically. ${ }^{14}$ At a practical level, responses were first categorised as either: (i) non-crisis-related or (2) relating directly to COVID-19 response. NVivo V.12 software ${ }^{15}$ was then used to develop a thematic framework based around free coding of the two corpuses. A hierarchy of importance was developed based on the number of times issues relating to a given theme were reported. Analysis was led by the research fellow undertaking the wider Facemums service evaluation with input from the wider project team. For clarity, some of the respondent examples given in this article contain minor edits (eg, typo corrections). These are not marked. Any significant edits, such as shortened sections or the anonymising of names and places, are indicated using square brackets.

\section{Patient and public involvement}

As a funded pilot intervention, Facemums has an advisory group and a steering group. Both of these have active user representation (including midwives and women accessing maternity services). Group members were closely involved in the design and implementation of the service evaluation that this survey forms part of.

\section{RESULTS}

Of 320 women who were members of an active Facemums group, 156 completed the survey, giving a $49 \%$ response rate. One hundred and four $(66 \%)$ of participants who completed the survey also wrote a response to the freetext question.

\section{Closed questions}

The four closed questions included in the survey were: (1) 'I have been accessing my Facemums group more frequently during the COVID-19 period'; (2) 'I have been able to access more pregnancy-related information from my Facemums group than from my face-to-face care providers during COVID-19'; (3) 'I feel having my Facemums group has improved my antenatal care during COVID-19'; (4) 'It has been easier to contact my Facemums group for information/advice than my face-to-face provider during COVID-19'. Table 1 summarises the replies to the closed questions.

\section{Qualitative data: free-text comments}

The free-text item at the end of the survey was 'Do you have any general comments on how your group has supported you during COVID-19?'. One hundred and four participants $(66 \%)$ provided responses that varied in length from 2 to 170 words.

\section{Short generic and non-crisis-related comments}

A small proportion of women $(n=5 / 5 \%)$ chose to give a relatively short or generic response that did not specifically refer to the COVID-19 situation. For example: 'Really useful' (participant 14); 'Fantastic support' (Participant 18); and 'They're great' (Participant 83). Twenty-six participants $(25 \%)$ gave longer one or two sentence responses that referred to the current situation in general but not to a specific element or issue. All of these short or generic comments were positive. For example: 'All the Facemums staff have been incredible, I'm so grateful to be involved' (Participant 3).

\section{Comments relating to COVID-19 response}

Key themes to emerge related to: (1) information provision and verification; (2) managing and reducing feelings of isolation; (3) service specific issues, including crisis adaptations; and (4) impact on routine care.

\section{Information provision and verification}

The majority of participants who responded to the survey $(\mathrm{n}=78 / 75 \%)$ directly referred to aspects of information provision in their comments, either in isolation or connected to other concerns. Key aspects related to the respondents' awareness of the increasing (crisis-related) demands on midwives in the hospital setting. Facemums groups were seen to fill an important gap in support, and do so with urgency, also offering alternative access to professional care in a time where some felt that their queries may be unnecessary or burdensome within the crisis context.

There has been a lot of information and advice that I would not have bothered the community midwives for at this time. It has been great for letting me know that the decisions being made are in the best interests of patients. (Participant 2)

Invaluable support and information. Providing us up to date government advice and info on the trusts response. I have not received any other updates from the trust other than through Facemums. I was only called two days before I was due to start antenatal to say it was cancelled however, I knew this already via Facemums. The Facewives and mums have been an amazing support through this challenging time. (Participant 12)

The quality of shared information and the significance of professional validation was crucial to women 
Table 1 (A) 'I have been accessing my Facemums group more frequently during the COVID-19 period'; (B) 'I have been able to access more pregnancy-related information from my Facemums group than from my face-to-face care providers during COVID-19'; (C) 'I feel having my Facemums group has improved my antenatal care during COVID-19'; (D) 'It has been easier to contact my Facemums group for information/advice than my face-to-face provider during COVID-19'

Rank value Option Count \% of respondents

(A)'I have been accessing my Facemums group more frequently during the COVID-19 period'

\begin{tabular}{|c|c|c|c|c|c|}
\hline & & & & Mean rank & 4.03 \\
\hline 1 & Strongly disagree & 1 & 0.5 & Variance & 0.86 \\
\hline 2 & Disagree & 12 & 8 & SD & 0.93 \\
\hline 4 & Agree & 65 & 40.5 & Upper quartile & 5.0 \\
\hline 5 & Strongly agree & 55 & 36 & & \\
\hline
\end{tabular}

(B)'I have been able to access more pregnancy related information from my Facemums group than from my face-toface care providers during COVID-19'

\begin{tabular}{|c|c|c|c|c|c|}
\hline & & & & Mean rank & 4.21 \\
\hline 1 & Strongly disagree & 1 & 0.5 & Variance & 0.73 \\
\hline 2 & Disagree & 6 & 4 & SD & 0.85 \\
\hline 3 & Neither agree or disagree & 20 & 13 & Lower quartile & 4.0 \\
\hline 4 & Agree & 62 & 40 & Upper quartile & 5.0 \\
\hline 5 & Strongly agree & 67 & 42.5 & & \\
\hline
\end{tabular}

(C)'I feel having my Facemums group has improved my antenatal care during COVID-19'

\begin{tabular}{|c|c|c|c|c|c|}
\hline & & & & Mean rank & 4.36 \\
\hline 1 & Strongly disagree & 1 & 0.5 & Variance & 0.5 \\
\hline 2 & Disagree & 1 & 0.5 & SD & 0.72 \\
\hline 3 & Neither agree or disagree & 12 & 8 & Lower quartile & 4.0 \\
\hline 4 & Agree & 69 & 44 & Upper quartile & 5.0 \\
\hline 5 & Strongly agree & 73 & 47 & & \\
\hline
\end{tabular}

(D)'It has been easier to contact my Facemums group for information/advice than my face-to-face provider during COVID-19'

\begin{tabular}{llclll} 
& & & Mean rank & & \\
1 & Strongly disagree & 1 & 0.96 & Variance & 0.82 \\
2 & Disagree & 6 & 4 & SD & \\
3 & Neither agree or disagree & 43 & 27 & Lower quartile & 3.9 \\
4 & Agree & 54 & 35 & Upper quartile \\
\hline 5 & Strongly agree & 52 & 33.5 & & 5.0 \\
\hline
\end{tabular}

who responded to the survey. In turn, respondents noted how levels of trust and access to verified information and expertise had a direct impact on levels of stress and anxiety, particularly in relation to that caused by misinformation.

It's hard with a lot of uncertainty, and I've found I've been avoiding the normal pregnancy forums as there's so much misinformation, and everything is different across different trusts and lots of very anxious people I find they were just stressing me out. I found it invaluable to have a place to come to with Information both valid to my birthing centre and that I can trust. This group has lowered my anxiety massively in relation to Covid-19. (Participant 103)
A number of respondents highlighted that social media based support does not suit everyone and that for some people there was the potential for certain types of group discussion to increase levels of anxiety. In this regard, the presence of the midwife moderators, distinguished Facemums from 'normal pregnancy forums' (Participant 103) and was crucial in terms of providing reassurance.

I think there are some negatives to the group where some mums were panicking about the situation which made me more concerned than I was before. Midwives were reassuring though. It's also easy to get regular updates on here which is useful given the rapidly changing status. (Participant 59) 
To be honest I have been avoiding these kinds of groups more since Covid, because I find them to be a source of stress. I have been checking my notifications for the group though. (Participant 34)

Similarly, for some respondents who were able to maintain regular contact with their assigned midwife during the crisis, the appeal of and need for a dedicated online service was not as marked. In some Trusts and individual maternity units where online information provision was already well integrated, mothers reported using these alongside or instead of Facemums.

I find it quite easy to speak to my [community] midwife about any concerns however I haven't really referred to Facemums about Covid 19 much as I feel like the information we have been provided is something I can google, it's sometimes faster to google things and not panic other people, as I know the Facewives aren't always able to respond straight away. I've noticed the info I have been given has been the same articles I've read online. (Participant 48)

The hospital has set up a Facebook group for updates which has been useful, this is separate from the Facemums group and has been more useful. (Participant 50)

\section{Managing and reducing feelings of isolation}

Along with the provision of professionally validated information, a key aim of the Facemums initiative has been to facilitate the development of virtual communities of practice where pregnant women can connect with one another and offer mutual psychological and emotional support. In the context of COVID-19, for many women who responded to the survey, this function gained added significance.

It's been my lifeline in these uncertain times. I feel closer to [group Midwife Moderator name] than any other midwife that has cared for me in this pregnancy and my last. I go to them first before anyone for support. (Participant 64)

[During Covid] it's been even more important having a group of women who are in the same position as you as these are very extreme and unique circumstances and it's very easy to feel very alone but the group has helped with this. [Having the group] has made us feel more secure. (Participant 24)

... [It's] just been great to have the support from the other mums all going through the same thing, plus the Facewives regularly alerting us to key guidance and other bits and pieces related to Covid-19 and pregnancy. I would have felt very lost and honestly quite anxious without the Facemums group. (Participant 76)

Service specific issues, including crisis adaptations

As the COVID-19 crisis developed, individual midwife moderators were able to capitalise on functions built in to the social media platform (such as livestreaming) to respond rapidly to required changes in practice and deliver trust-specific information.

They have been excellent. The 2 hour (!) Facebook live [livestreaming event] was detailed, thorough and specific to our trust which was invaluable at a time when antenatal classes and hospital tours are cancelled indefinitely. (Participant 55)

[They] have been giving us regular updates on not only what advice there is for pregnant ladies during covid-19, but they are keeping us up to date on what is happening at our hospital. This has been very reassuring. It has really helped that they are giving us lots of information and in particular doing Facebook lives [livestreaming event] on topics we want to know about - this has been amazing, as my antenatal classes were all cancelled. (Participant 41)

The ability of mothers to easily contact a professional midwife online and be guaranteed a response is a key feature of the Facemums model. ${ }^{12}$ As restrictions developed on some aspects of face-to-face maternity care, this feature became particularly important to a number of respondents:

In today's society it's much more accessible to post to a Facebook group than trying to call a hospital or a community midwife. Much of my generation feel more comfortable using social media than other communication channels. I think the group is a great tool for asking for information that is not 'critical' for example, If there was a medical emergency, I would ring the hospital or midwife etc. but I wouldn't ring them for something more trivial although it may still be something important to my pregnancy care. I also feel that the group has been a vital part of communication through this Covid pandemic, they have posted updates of information and best practice for pregnant women as soon as they are available - I haven't received any communication around Covid from either the hospital or community midwife. When there has been a change in care due to Covid it has not always been explained to me why by the hospital, but I have been able to get the answers from the group. (Participant 44)

\section{Impacts on routine care}

In terms of the practical impact that COVID-19 has had on maternity services, the primary concerns of survey respondents were restrictions on community midwife contact, the cancellation of antenatal classes and a feeling of general disconnection from routine healthcare support. Respondents were keen to express that while some aspects of routine midwifery care were lacking or slower, this was to be expected. Online access to support was seen as helping to fill this gap. 
I haven't yet had the same midwife throughout my care and therefore no community midwife contact despite the Covid-19 outbreak and it is now even more unlikely, understandably due to the current situation, that I will see the same one throughout the rest of my pregnancy. Having this group has ensured I can ask questions, gain information and receive care and friendly advice from both the Facewives and the other participants. (Participant 10)

I would be absolutely lost without this group during this time of pandemic. The Facewives are incredibly helpful, going above and beyond what I could expect of them. They are unbelievably efficient at monitoring and responding to the chats and questions on the group. Without them I would have missed appointments and felt entirely abandoned by the system as they have resolved issues for me where I couldn't get in contact with assigned midwife etc. They have been the ONLY consistent support I have had during my pregnancy and the ONLY assurance and place to go that I have that I can find out what I need or what's important or seek help. (Participant 56)

Whilst it's nobody's fault that Covid-19 has caused all the classes to be cancelled and midwife appointments to be cut short/moved to telephone. It's been hard! I'd go so far as saying it's actually quite distressing to feel robbed of these events, especially after everyone telling me from the start how important antenatal parent education classes are and to book on straight away! Having the group has been a godsend not only for community with other mums around the same stage as me, but the fact that it's overseen by qualified midwives is just amazing. (Participant 17)

\section{DISCUSSION}

The women who took part in this study were all very familiar with using social media and the internet as part of their everyday lives. ${ }^{16}$ Similarly, they did not start using this particular social media service because of the current pandemic and neither was it originally designed with this exceptional situation in mind. What is clear, however, is that in several key ways, pregnant women who would ordinarily have been using a range of maternity services have found access to Facemums extremely useful.

A major effect of the COVID-19 response has been to impose restrictions on face-to-face healthcare interactions of all kinds. In maternity care, this has meant that many of the service encounters that pregnant mothers can expect to have-ranging from antenatal classes right through to routine meetings with their community midwife-have been cancelled or restricted to emergency contact only. At the point at which this study was initiated, approximately 3 weeks into UK lockdown, the midwife moderators running existing groups were already capitalising on functions built in to the Facebook platform (such as livestreaming) to deliver trust-specific information. This led a high proportion of women who completed our survey $(82.5 \%)$ to agree or strongly agree that during COVID-19 they had been able to access more pregnancy related information from their Facemums group than from faceto-face providers. This, coupled with the $91 \%$ of respondents who agreed or strongly agreed that having access to a group had improved their antenatal care during COVID-19, gives an indication of the positive impact that Facemums had on the maternity experience of women who were using it during the crisis.

What appears to have made the Facemums model so appealing to mothers during the crisis was that it took familiar elements of online engagement, such as easy access to a vast amount of information and the ability to connect instantly with other people but lessens some of its key drawbacks. In particular, it offered individualised and reliable responses ${ }^{17}$ and allowed mothers to verify the credibility of information that was shared. ${ }^{18}{ }^{19}$ It has been established in previous (ie, pre-COVID-19) evaluations of this and other comparable online interventions ${ }^{11}$ that the quality, provenance and validity of information is of primary concern to users. This was confirmed by the responses we collected. Participants also highlighted how, in the context of COVID-19, the option to be able to use the group as their primary source of maternity-related information and support helped reduce information overload and confusion and do so in a timely manner without instigating feelings of being burdensome on already stretched services. Combined, this resulted in reduced stress and anxiety.

Although being a member of a group does not appear to entirely replace general internet searches for information on pregnancy and motherhood, when participants use Google to find information, they often then ask their group to verify what they have found. Underlying this verification is the knowledge that a midwife moderator will also see the interaction and, even if they were not directly posting contributions to a particular thread, will be there to step in and clarify any misinformation.

It appears that one effect of the COVID-19 response has been to greatly heighten the need for people-not only pregnant women-to use the internet as a source of healthcare information and support. ${ }^{20} 21$ This was reflected in many of the free-text comments we collected. However, a number of our participants also highlighted that by their nature, social media-based interventions might not suit everyone. It appears that in the atmosphere of heightened anxiety that the crisis has generated, there is the potential for open discussions between individuals who are already likely to be some of the most stressed and anxious to make things worse. Similarly, for some respondents who were able to maintain regular contact with their assigned midwife during the crisis, the appeal of and need for a dedicated online service was not as marked. In some Trusts and individual maternity units where online information provision was already well integrated, mothers reported that they still preferred to use these alongside or instead of Facemums. 


\section{CONCLUSIONS}

Prior to COVID-19, membership of a Facemums group offered a safe space for pregnant women to share and access information. This study demonstrates that although this professionally mediated social media model of maternity support was already popular with users, it was, and remains, well positioned to help midwives and pregnant mothers meet the unprecedented challenges of antenatal care during the pandemic. A strength of the Facemums model has been that it required very little modification to adapt to the emerging crisis. It seems likely that postpandemic, the service will continue to operate in fundamentally the same way, although it is anticipated that the increased levels of usage that have now been established may become a feature of 'new normal' antenatal care for a significant time to come.

Acknowledgements The full title of the main study is: Facemums 2018 - Bringing relational continuity to the home through social media.

Contributors $\mathrm{JJ}$ and LJ designed the survey and collected the data. JC assisted with the survey design, conducted the analysis and led on writing the paper. DB project managed the Facemums service, assisted with the survey design and delivery and cowrote the paper. LC and RM originally designed and supervised the service. All authors commented on a final draft of the paper.

Funding The project is funded by Health Education England (HEE).

Disclaimer The views expressed in this publication are those of the authors and not necessarily those of HEE or the Department of Health.

Competing interests None declared.

Patient and public involvement Patients and/or the public were not involved in the design, or conduct, or reporting, or dissemination plans of this research.

Patient consent for publication Not required.

Ethics approval The study formed part of an ongoing service evaluation, which was approved by Greater Manchester West NHS Research Ethics Committee. REC reference: 19/NW/0011. IRAS project ID: 257015.

Provenance and peer review Not commissioned; externally peer reviewed.

Data availability statement Data are available on reasonable request. The survey data can be provided on request from the authors. Due to ethical concerns, the qualitative data set (free-text responses) cannot be made openly available.

Open access This is an open access article distributed in accordance with the Creative Commons Attribution Non Commercial (CC BY-NC 4.0) license, which permits others to distribute, remix, adapt, build upon this work noncommercially, and license their derivative works on different terms, provided the original work is properly cited, appropriate credit is given, any changes made indicated, and the use is non-commercial. See: http://creativecommons.org/ licenses/by-nc/4.0/.

ORCID iD

John Chatwin http://orcid.org/0000-0003-3091-9117

\section{REFERENCES}

1 Knite V. Covid-19: beware online tests and cures, experts say. The guardian Tue 31 March, 2020.

2 Liu S, Yang L, Zhang C, et al. Online mental health services in China during the COVID-19 outbreak. Lancet Psychiatry 2020;7:e17-18.

3 Kiley R. Does the Internet harm health? some evidence exists that the Internet does harm health. BMJ 2002;324:238.

4 McCarthy R, Byrne G, Brettle A, et al. Midwife-moderated social media groups as a validated information source for women during pregnancy. Midwifery 2020;88:102710.

5 NHS. Available: https://www.nhs.uk/

6 Lagan BM, Sinclair M, Kernohan WG. Internet use in pregnancy informs women's decision making: a web-based survey. Birth 2010;37:106-15.

7 Olson CM. Tracking of food choices across the transition to motherhood. J Nutr Educ Behav 2005;37:129-36.

8 Johnson SL, Safadi H, Faraj S. The emergence of online community leadership. Inform System Res 2015;26:165-87.

9 Eysenbach G, Powell J, Englesakis M, et al. Health related virtual communities and electronic support groups: systematic review of the effects of online peer to peer interactions. BMJ 2004;328:1166-6.

10 Office of national statistics, 2018. Available: https://www.ons.gov.uk/ [Accessed 29 Nov 2018].

11 McCarthy R, Choucri L, Ormandy P, et al. Midwifery continuity: the use of social media. Midwifery 2017;52:34-41.

12 Chatwin J, McCarthy R. Widening access in online maternity support. Practicing Midwife 2020;23:5.

13 Jisc Online surveys (formerly BOS). Available: https://www. onlinesurveys.ac.uk/

14 Braun V, Clarke V. Using thematic analysis in psychology. Qual Res Psychol 2006;3:77-101.

15 A place to organize, store and analyze your data. Available: https:// www.qsrinternational.com/nvivo-qualitative-data-analysis-software/ home

16 Sinclair M, Lagan BM, Dolk H, et al. An assessment of pregnant women's knowledge and use of the Internet for medication safety information and purchase. J Adv Nurs 2018;74:137-47.

17 Walsh T. "Doing midwifery my way" - Triumphs and challenges of 8 years in a small private practice. Women and Birth 2018;31:S23-4.

18 Lewallen LP, Côté-Arsenault DY. Implications for nurses and researchers of Internet use by childbearing women. Nurs Womens Health 2014;18:392-400.

19 Jay A, Thomas $\mathrm{H}$, Brooks F. Induction of labour: how do women get information and make decisions? findings of a qualitative study. $\mathrm{Br} \mathrm{J}$ Midwifery 2018;26:22-9.

20 Anthony $B$. Use of telemedicine and virtual care for remote treatment in response to COVID-19 pandemic. J Med System 2020;44:1-9.

21 Chan AKM, Nickson CP, Rudolph JW, et al. Social media for rapid knowledge dissemination: early experience from the COVID-19 pandemic. Anaesthesia 2020;75:1579-82. 